Article

\title{
Supply Chain Optimization for Energy Cogeneration Using Sugarcane Crop Residues (SCR)
}

\author{
Leonardo Rivera-Cadavid, Pablo Cesar Manyoma-Velásquez $(\mathbb{D}$ and Diego F. Manotas-Duque *(1) \\ School of Industrial Engineering, Universidad del Valle, Cali 13 No 100-00, Colombia; \\ leonardo.rivera.c@correounivalle.edu.co (L.R.-C.); pablo.manyoma@correounivalle.edu.co (P.C.M.-V.) \\ * Correspondence: diego.manotas@correounivalle.edu.co; Tel.: +57-2-321-21-67
}

Received: 31 October 2019; Accepted: 19 November 2019; Published: 21 November 2019

\begin{abstract}
Access to clean and non-polluting energy has been defined as a Sustainable Development Goal (SDG). In this context, countries such as Colombia have promoted policies and incentives for the implementation of energy projects with non-conventional sources of energy. One of the main energy alternatives available is related to the use of residual biomass left by agribusiness supply chains, such as sugarcane. In Colombia, sugar cane is grown and harvested all year round, due to the local tropical climate. The model we propose addresses the question of the selection of the plots whose crop residue will be transported for energy production on a given day. We built a Mixed-Integer Programming model to decide which plots to harvest on a given day. Although no additional energy is generated in the model, the results show that it is feasible to replace all coal used in the boilers with sugarcane crop residues (SCRs) for power cogeneration.
\end{abstract}

Keywords: Sugarcane Crop Residues (SCRs); cogeneration; optimization of bioenergy supply chain decisions

\section{Introduction}

\subsection{Background and Motivation}

Countries all over the world are focusing on renewable energy resources as an attractive option for achieving future energy security. Access to clean and non-polluting energy has been defined as a Sustainable Development Goal (SDG). In this context, many countries are promoting strategies to diversify the power generation mix considering clean energy projects to mitigate the climate change originated by greenhouse gas emissions from fossil fuel consumption. To achieve this purpose, one of the main energy resources available is the biomass. Biomass is defined as "a biological material derived from living or recently living organisms," There are three main biomass types-(1) first-generation biomass, which includes edible crops, such as corn and sugarcane; (2) second-generation biomass, which includes wood, organic waste, food waste, and specific biomass crops residues; and (3) third-generation biomass, mainly based on algae [1]. In this paper, we present a model of supply-chain design for sugarcane crop residues in the sugar industry. Currently, the sugar industry has been participating in power cogeneration projects. Usually, in these projects, sugar factories use a mix of fuels, mainly bagasse- $\mathrm{a}$ by-product of the production process - and coal. There is an opportunity to include part of the sugarcane crop residues (SCRs) originated in crop activities in the mix. The use of SCRs arises as a possible substitute for the coal used in boilers. Authors like those of reference [2] have made a complete analysis of the state of research and trends in biomass for renewable energy from 1978 to 2018, focusing on the current situation and future trends. This information is very useful for making decisions about the future of scientific policy in the field of renewable energy projects. 
The use of agricultural crop residues in electrical co-generation processes has been widely discussed in the literature. Some authors, such as those of reference [3], systematically describe energy needs and targets, biofuel feedstocks, conversion processes, and provide a comprehensive review of biomass supply chain (BSC) design and modeling. In reference [4], the authors describe the key challenges and opportunities in the modeling and optimization of biomass-to-bioenergy supply chains. The optimization process of a biomass supply chain is essential to overcome barriers and uncertainties that may inhibit the development of a sustainable and competitive bioenergy market. In reference [5], the authors give an overview of the optimization techniques and models, focusing on decisions regarding the design and management of the upstream segment of the biomass-for-bioenergy supply chain. Another research approach is related to the integration of different optimization objectives in biomass supply chain models. There is a recent tendency to integrate economic, environmental, and social aspects in the evaluation and optimization of biomass supply chains. Some authors (for example, those of reference [6]) have reviewed the studies that assessed or optimized economic, social, and environmental aspects of forest biomass supply chains for the production of bioenergy and bio-products.

The structure of this paper is as follows: In Section 1.2, we present a literature review of bioenergy supply chain optimization decisions. In Section 2, the optimization model is explained, taking into account the parameters, variables, objective functions, and constraints. Sections 3 and 4 present the results and discussion. Section 5 presents conclusions and future research options. The Julia code of the model is included as an appendix.

\subsection{Literature Review-Bioenergy Supply Chain Optimization}

For tropical and subtropical countries, sugarcane is one of the most important crops, from economic, social, and environmental points of view. The area and productivity of sugarcane differ from one country to another. It is estimated that this crop is grown in 200 countries, with Asia being the region with the greatest contribution to world production (44\%), while South America contributes $34 \%$, including Brazil, the largest sugarcane producer in the world, accounting for $25 \%$ of total world production [7]. Ninety-two percent of the sugarcane harvested in the world is directed toward sugar production. Sugar production and trade flows are concentrated in large producers, exporters, and importers, such as Brazil, India, Thailand, the European Union, Australia, and China [8].

There are different studies about the use of sugarcane crop residues in the bioenergy production. According to reference [9], sugarcane crop residues can be used as raw material in the production of bioenergy or biofuels. The use of these resources can avoid environmental problems and concerns. Each country has its unique set of crop residues that can be used for the generation of biofuels or bioenergy. In reference [10], the authors assess the bioelectricity potential from ecologically available sugarcane straw in the state of Sao Paulo (Brazil) considering the spatial distribution of sugarcane fields, the spatial variation of sugarcane yield, the location, and the milling data of each mill. The bioelectricity potential from ecologically available sugarcane straw is estimated to be between 18.7 and 45.8 TWh in Sao Paulo, equal to $22-37 \%$ of the electricity demand. Reference [11] presents a techno-economic analysis of upgraded sugarcane bio-refineries in Brazil, aiming at utilizing surplus bagasse and cane trash for electricity and/or ethanol production. This study investigates the trade-off on sugarcane biomass use for energy production-bioelectricity versus $2 \mathrm{G}$ ethanol production. In references [12-14], the authors value the cogeneration potential of the sugar industry as a new business model for sugar mills.

The main activities in the sugarcane industry are crop, harvest, and factory (sugar mill plant and distilleries). SCR is a by-product of the crop activities (Figure 1). SCRs are not used in the amount required by current circumstances. It has been estimated that, for each ton of cane, between 70 and $80 \%$ are clean stems, and the rest is what is called crop residues (green leaves, dried leaves, buds, etc.). The SCR can be used for different purposes, such as soil improvement, animal feed, energy generation, and other applications (boards, binders for construction, handicraft products, etc.). These residues, 
obviously, constitute a renewable energy source, but their use depends largely on aspects such as collection, transport, storage, and technological processes to transform them.

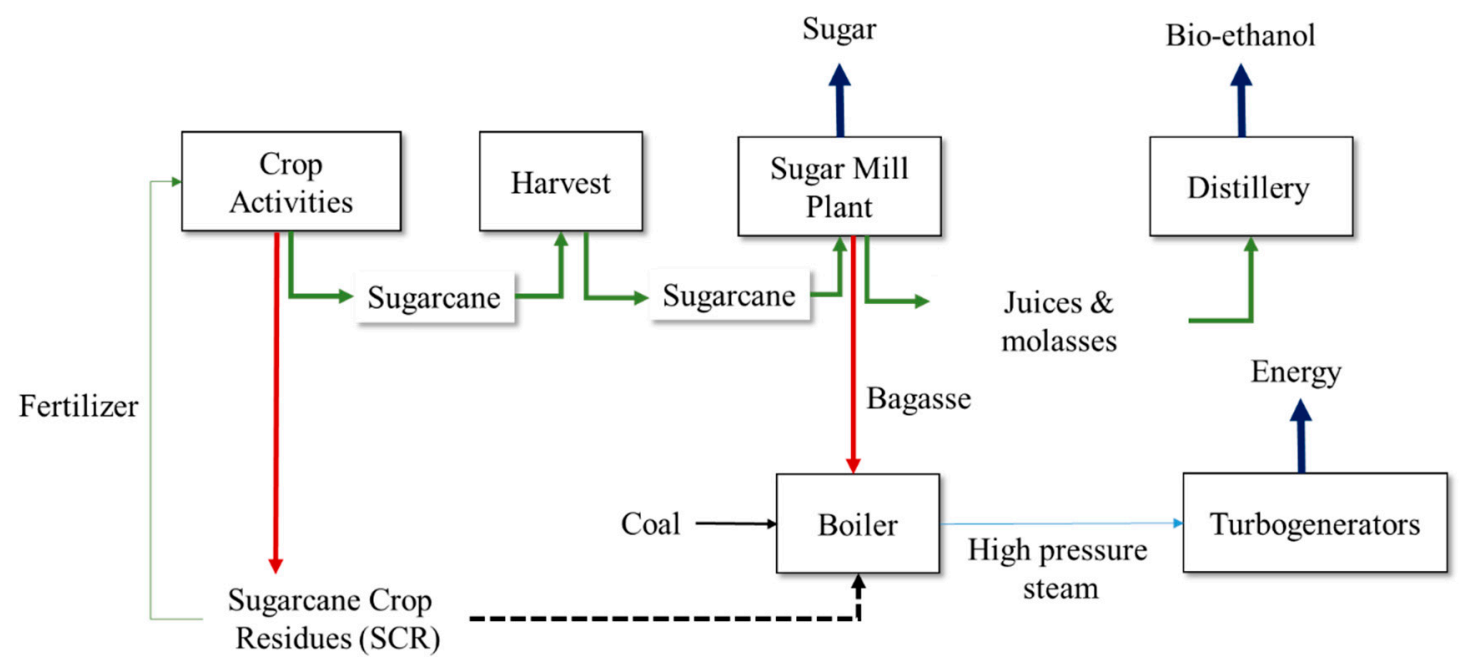

Figure 1. Cogeneration process and main activities in the sugar industry.

The collection process, traditionally, can be done in two places-in collection centers (cleaning stations) or in the field itself. Among the aspects related to residue handling, one of the most important is transport due to its technical-economic impact [15]. Agricultural residue is a low density material, and the amount that can be moved is limited by volume and not by weight. Therefore, the use of all available space is essential for transport economics. For this, some mechanical treatments have been carried out that can eliminate the geometric heterogeneity of the residue and make compaction possible for later use. Finally, some authors warn of the need to keep $50 \%$ of the residual in the field to preserve appropriate soil conditions [16].

In Colombia, it is estimated that the cultivation of sugarcane has a production potential of SCR per ton of cane close to $25 \%$. This availability can be affected by factors such as: variety of cane planted, crop agro climatic conditions, agronomic practices and the harvest types, among others [17].

Table 1 presents the potential production of SCR in the state of Valle del Cauca, depending on the crop variety.

Table 1. Percent of sugarcane residue (SCR) by sugarcane variety.

\begin{tabular}{cc}
\hline Variety & $\begin{array}{c}\text { Total } \\
\text { (t SCR/t cane) }\end{array}$ \\
\hline CC 01-1940 & 0.2657 \\
CC 85-92 & 0.2479 \\
CC 93-4418 & 0.2624 \\
Others & 0.2587 \\
\hline \multicolumn{2}{c}{}
\end{tabular}

Under this structure and according to the amount of cane milled by the sector ( 25 million tons in 2018), approximately 6.25 million tons of SCR could be generated. However, total SCR that would actually be available is reduced to approximately 1.8 million tons per year due to crop type and the material that should be left in the field for soil conservation.

The SCR is an important energy resource for the sugar sector, but its use requires overcoming some technical challenges. One of these is its low energy content compared to traditional fossil fuels (higher calorific value: coal 25,983.7 KJ/kg; SCR 16,963.52 KJ/kg). Its low density $\left(100 \mathrm{~kg} / \mathrm{m}^{3}\right)$, added to its energy characteristics, makes the biomass volumes necessary to meet the energy need for a possible 
replacement of the coal used in the boilers of the sector significantly higher. In that sense, 1.53 tons of SCR are required to replace the calorific output of a ton of coal. This substitution has the clear benefit of reducing the carbon footprint, since 1 ton of coal would generate $2254 \mathrm{~kg}$ of equivalent $\mathrm{CO}_{2}$, while 1.53 tons of SCR generate $53.7 \mathrm{~kg}$ of equivalent $\mathrm{CO}_{2}$. [18]

The use of mathematical models to analyze the performance of the bioenergy supply chain has been widely studied in the literature. [19] Some authors, such as those of references [4,20,21], describe the key challenges and opportunities in modeling and optimization of biomass-to-bioenergy supply chains. According to references [5,22], one of the most important barriers to the development of a strong bioenergy sector is the cost of the biomass supply chain-specifically, the cost of SCR preparation, transport, and storage. In this context, the SCR supply chain cost competes directly with fossil fuel cost (coal). To overcome all these barriers and uncertainties, biomass supply chain optimization is essential.

Optimization decisions usually refer to the choice of highly productive non-food crops; the coordination of transportation, pre-treatment and storage at operational, tactical and strategic level; and the use of advanced efficient biomass-to-bioenergy conversion technologies to enable relevant reductions in environmental and biomass production costs [5].

A first step in the study of bioenergy supply chain optimization models is to build a taxonomy of the main optimization decisions for operational, tactical and strategic level [23]. Decisions related to biomass supply chain to energy conversion usually consider activities such as preparing and conditioning, transport, storage, and processing to energy generation. Normally, these decisions are taken at different levels. Some decisions can be strategic, such as technology type, kind of biomass, contracting, selection of transportation mode, supply network design, inventory levels, etc. At the tactical level the set of decisions includes storage conditions, vehicle routing, and harvest scheduling. The main biomass supply chain optimization decisions considered are presented in Figure 2 [3].

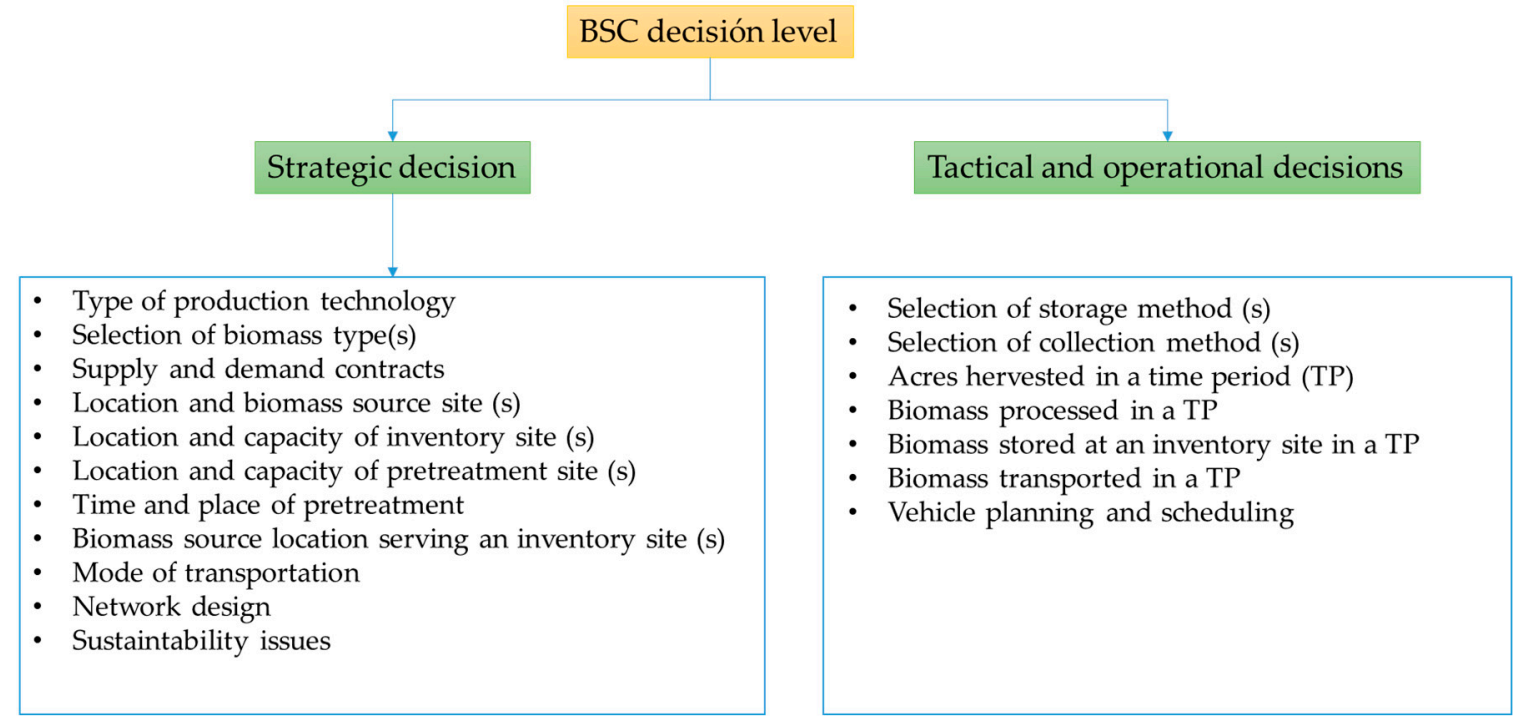

Figure 2. Biomass supply chain decision taxonomy [3].

On the other hand, when we consider the strategies to model biomass supply chain, usually we find stochastic, deterministic, hybrid, and IT-driven models. In the field of deterministic models, we can develope single and multiple objective models. The techniques used to solve the deterministic models include linear, mixed, integer linear and non-linear programming.

Specifically, in the sugar agro-industrial production chain, different strategies have been developed for the use of the biomass produced in the cultivation process. An important part of the total fiber produced by the sugarcane can be used as a renewable energy resource. The use of sugarcane crop residues as a substitute fuel in electric cogeneration systems begins to become a topic with great research potential in an effort to seek power generation systems with less environmental impact. 
Reference [24] presents an analysis of the potential of electricity generation from sugarcane crop residues in South Africa.

Some authors, like those of reference [25], propose a multi-objective integer linear programming optimization model to choose sugarcane varieties to minimize costs in the use of crop residue and simultaneously maximize the energy balance in such a process. In that paper, the authors considered different logistics costs. First, the cost to collect, compact, and load the truck with residual biomass of different sugarcane variety. In addition to these costs, the model considered included the fixed and variable costs associated with the movement of the cargo vehicles. The inclusion of sugarcane variety in the model introduces another dimension related with different quantities of SCR production.

Other papers in which information regarding decision optimization models associated with the sugarcane supply chain can be found include reference [26], which proposed a stochastic optimization model for sugarcane supply chain planning integrating sowing, growing, and harvesting operations. Reference [27] presented a model to improve the integration between harvest decisions and transportation decisions in sugar industry supply chain in Australia. Finally, in references [28,29], the authors proposed a decision support systems for the integration of supply chain decision in the sugar industry. The model developed was applied in the Cuban sugar industry.

\section{Model}

\subsection{Problem Description}

Harvesting crops leaves biomass on the ground (leaves, stems. and other plant materials). Sometimes, this residue is left in the plot to decompose and fertilize the soil [30]. In other cases, it is necessary to remove it for the process of soil preparation. In other instances, there are productive uses for the residue, such as producing biofuel or other agro-industrial products. In this case, we will consider the use of crop residue as combustible material for energy cogeneration.

In this paper, we use sugar cane as a hypothetical case study. In Colombia, sugar cane is grown and harvested all year round, due to the local tropical climate. Sugar mills harvest sugar cane according to a schedule that reflects the appropriate moment to do so for every plot. These companies have the logistics for harvesting sugar cane and transporting it to the mill. In addition to the resources devoted to this activity, it will be necessary to assign vehicles and operators to the logistics of collecting and transporting the crop residue. The model we propose addresses the question of the selection of the plots whose crop residue will be transported for energy production on a given day.

\subsection{The Process}

Sugar cane producers plant the plots staggered throughout the year. The crop takes 13 months on average to grow to maturity. The sugar cane mills build a daily schedule of the harvest of the plots in order to maximize the amount of sugar they will produce. To build this schedule, they must consider several factors, such as

- Distance from the plot to the factory;

- Sucrose contents in the crop;

- Availability of vehicles, harvesting equipment, and crews;

- In-factory waiting time for raw materials (the sugar contents in the canes start decreasing the moment they are cut, a process called inversion).

The harvest is executed using large mechanized harvesters or by hand by crews of human operators. The harvest leaves behind a substantial amount of biomass-the crop residue. This residue has been left in the field to decompose and fertilize the soil, but there is a growing interest in collecting and transporting it to the factory to burn it and generate electricity. 


\subsection{Using Crop Residue to Generate Electricity}

Sugar cane mills are working to become independent of the interconnected electricity grid; they can generate excess electricity and sell it back to the network at some times during the day. They are currently using coal in their boilers to generate steam (for the production process) and electricity for general usage [31,32]. The use of crop residue has some apparent advantages over coal, including

- Crop residue generates less $\mathrm{CO} 2$ equivalent than coal;

- Sugar cane mills have to purchase coal or exchange it for post-production byproducts. Crop residue is basically free.

\subsection{Mathematical Model}

We built a Linear Programming model to decide which plots to harvest on a given day. We will explain the elements of the model in the following subsections [32].

Sets: Plots scheduled to be harvested on a given day. Index: i.

\subsubsection{Parameters}

- $\quad T C R_{i}$ Tons of crop residue available on plot i.

- $C P_{i}$ : Energy value of the crop residue from plot i $\left(\mathrm{kw}^{*} \mathrm{~h} / \mathrm{ton}\right)$.

- $\quad P_{i}$ : Pollution caused by burning the crop residue from plot $\mathrm{i}\left(\mathrm{CO}_{2}\right.$ tons/ton of crop residue burned).

- $D_{i}$ : Rectilinear distance $(\mathrm{km})$ from plot i to the factory.

- FCOST: Fixed cost of collecting the crop residue from plot $\mathrm{i}(\$)$.

- COST: Transportation cost $\left(\$ /\left(\right.\right.$ ton $\left.\left.{ }^{*} \mathrm{~km}\right)\right)$.

- COAL: Baseline level of coal consumption (tons).

- $\quad C C L$ : Cost of coal (\$/ton).

- $\quad$ CPC: Energy value of coal $\left(\mathrm{kw}^{*} \mathrm{~h} / \mathrm{ton}\right)$.

- $\quad P O L$ : Pollution caused by burning coal ( $\mathrm{CO}_{2}$ tons/ton of coal burned).

- $C B O N D$ : Value of carbon bonds (\$/tons of $\mathrm{CO}_{2}$ removed) [33].

- $\quad S P E$ : Sales price of energy.

- $\quad V A V$ : Vehicles and crews available today for collection and transportation of crop residue.

\subsubsection{Detailed Information about the Parameters}

- $T C R_{i}$ : These are the tons of sugar cane crop residue that can be obtained from lot i. On average, it is possible to harvest 110 tons of sugar cane from a hectare of crop. From that, it has been estimated that the crop residue lies between $19 \%$ and $37 \%$ of that total weight [18]. The TCR from a given plot depends on its area, the variety of sugar cane grown, and the harvesting tools that are in use.

- $\quad C P_{i}$ : This represents the energy that can be obtained from a ton of crop residue. Reference [18] shows that sugar cane residue has a calorific potential of 16 kilojoules per ton. Converting this potential into kilowatts-hour, we get that on average sugar cane crop residue may generate $0.00444 \mathrm{kwh} / \mathrm{ton}$.

- $\quad P_{i}$ : Pollution caused by burning the crop residue from plot $i$. This parameter has been estimated as an average of $35.1 \mathrm{~kg}$ of $\mathrm{CO}_{2}$ equivalent per ton of crop residue burned [34].

- $\quad D_{i}$ : Rectilinear distance from a plot to the sugar cane mill. The structure of plots and roadways is predominantly rectilinear. For a factory located at $(A, B)$ the distance to a plot with coordinates $\left(x_{i}, y_{i}\right)$ would be $D_{i}=\left|A-x_{i}\right|+\left|B-y_{i}\right|$ (Figure 3). 


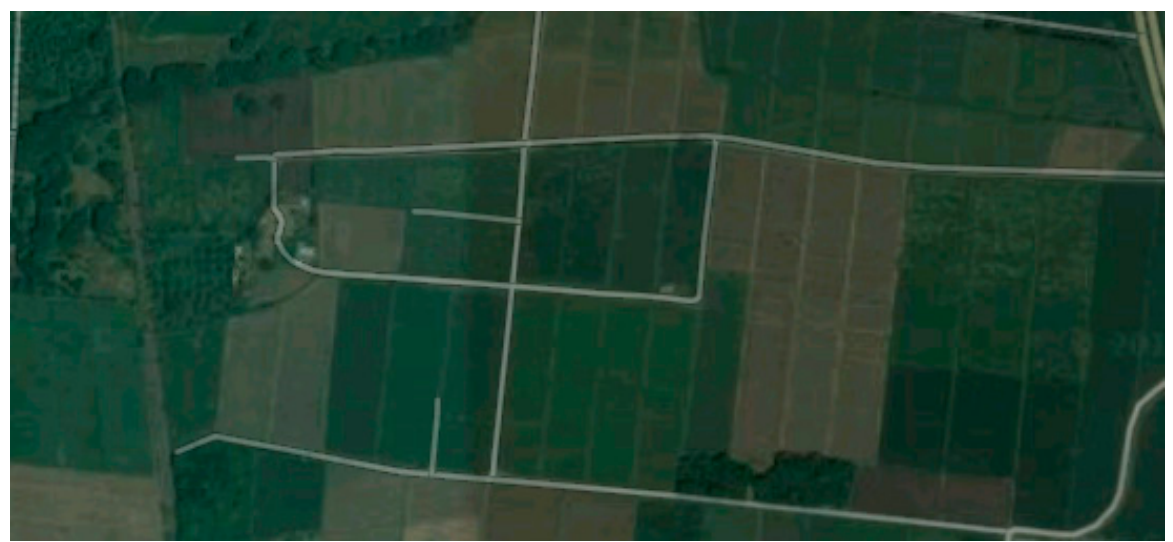

Figure 3. Sugar cane plots. Source: Google Maps.

- FCOST: Fixed cost of collecting the crop residue from plot $\mathrm{i}(\$)$. This is the cost related to fixed salary of the driver of the vehicle and the cost of ownership of said vehicle. It depends neither on the tons transported nor on the distance. We have calculated this cost at \$32 USD per trip, assuming three trips per day per crew. We calculated this cost considering the fixed salaries of the crews, assuming full utilization of their work, and also considering the cost of ownership of the vehicles required for the transportation of the sugarcane crop residue. The cost of operation of the vehicles is included in the parameter COST.

- COST: This is the variable transportation cost. We have calculated its value at \$0.115 USD per ton-km.

- COAL: This is a user-supplied value. For our exercise we will use a value of 100 ton/day as a baseline (obtained from an actual sugar cane mill).

- CCL: Cost of acquisition of coal in \$/ton USD. This cost may vary according to the sources the individual company uses to acquire its coal. There are different acquisition strategies, including long-term contracts, open market contracts and the exchange of bagasse for coal with the paper mills. For this model, we used \$75/ton USD.

- CPC: Energy value of coal ( $\mathrm{kwh} / \mathrm{ton})$. The coal used by sugar cane mills has a calorific power of $0.00666 \mathrm{kwh} / \mathrm{ton}$ on average.

- POL: Pollution caused by burning coal $\left(\mathrm{CO}_{2}\right.$ tons/ton of coal burned). This value has been estimated as 2.66 tons of $\mathrm{CO}_{2}$ per ton of coal burned [34].

- $C B O N D$ : Value of carbon bonds (\$/tons of $\mathrm{CO}_{2}$ removed). We will use $\$ 25$ USD per ton of equivalent $\mathrm{CO}_{2}$, as this is close to the average in the first part of 2019 [33].

- SPE: Sales price of energy. In Colombia, this price is currently $\$ 0.028 \mathrm{USD} / \mathrm{kwh}$ [35].

- $\quad V A V$ : Trips for residue collection and transportation available today. In our example, VAV ranges between 15 and 25 for any given day.

\subsubsection{Variables}

- $y_{i}$ : Binary: 1 if the residue from plot $i$ is collected, 0 if not.

- $x_{i}$ : Amount of tons of crop residue collected from plot i.

- cpur: Tons of coal burned today.

- bond_income : Income obtained through the sale of green bonds.

- $\quad$ elec_sold : Electricity sold.

- coal_savings : Savings realized if the coal purchased is less than the baseline.

- fixed_transp : Total fixed transportation costs.

- var_transp : Total variable transportation costs. 


\subsubsection{Objective Function: Maximize $Z=$ Total Profit}

The total profit is the result of the sum of the income from the sale of carbon credits, income from the sale of energy, and savings from the replacement of coal, less the fixed and variable costs of transport and logistics (Equation (1)).

$$
\text { Total Profit }=\text { bond_income }+ \text { elec_sold }+ \text { coal_savings }- \text { fixed_transt }- \text { var_transp }
$$

Revenue from carbon credits is estimated from the reduction of tons of carbon dioxide by replacing coal as fuel in boilers (Equation (2)).

$$
\text { bond_income }=\left(C O A L * P O L-\sum_{i}\left(x_{i} * P_{i}\right)-c p u r * P O L\right) * C B O N D
$$

The marginal revenues from the sale of energy due to the replacement of coal by SCR. This substitution reduces the variable cost of generation and increases the probability of plant use (Equation (3)).

$$
\text { elec_sold }=\left(\sum_{i}\left(x_{i} * C P_{i}\right)+(\text { cpur }-C O A L) * C P C\right) * S P E
$$

Savings derived from lower coal consumption as a boiler fuel (Equation (4)).

$$
\text { coal_savings }=(C O A L-\text { cpur }) * C C L
$$

The fixed and variable transport cost are presented in Equations (5) and (6).

$$
\begin{aligned}
& \text { fixed_transp }=\sum_{i}\left(y_{i} * F C O S T\right) \\
& \text { var_transp }=\sum_{i}\left(x_{i} * D_{i} * \text { COST }\right)
\end{aligned}
$$

\subsubsection{Constraints}

(1) The new level of pollution must not be larger than the baseline (Equation (7)).

$$
\text { cpur } * P O L+\sum_{i}\left(x_{i} * P_{i}\right) \leq C O A L * P O L
$$

(2) The electricity generated today must not be less than the baseline (Equation (8)).

$$
\sum_{i}\left(x_{i} * C P_{i}\right)+(\text { cpur } * C P C) \geq C O A L * C P C
$$

(3) The number of plots in which to collect the crop residue is limited by the number of crews available (Equation (9)).

$$
\sum_{i} y_{i} \leq V A V
$$

(4) If a plot is not selected, no crop residue will be collected from it (Equation (10)).

$$
x_{i} \leq T C R * y_{i} ; \forall i
$$

\section{Results}

The main results obtained are showed in the Table 2. The total profit is $\$ 13,708$ USD. The plots collected are plot 2, plot 5, plot 9, plot 11, and plot 16 (Table 2). The model exactly replaces the energy generated by coal with energy from the crop residue. There is an interesting opportunity to obtain additional financial resources associated with the participation in the carbon bond market from the replacement of coal in the boiler. The model does not recommend the collection of more crop residue to generate electricity and sell it back to the grid. This is due to the fact that in a country like Colombia, 
the marginal cost of electricity generation is determined through optimal economic dispatch. Given the predominant character of hydro power generation sources in the electrical system, thermal power plants have less opportunity to be used.

Table 2. Model outputs.

\begin{tabular}{|c|c|c|c|c|c|}
\hline \multirow{2}{*}{$\begin{array}{c}\text { Total Profit } \\
\text { Plots collected }\end{array}$} & \multicolumn{5}{|c|}{$\$ 13,708.04$ USD } \\
\hline & $\mathrm{P} 2$ & P5 & P9 & P11 & P16 \\
\hline Tons collected & 30.0 & 26.0 & 21.0 & 30.8 & 36.0 \\
\hline Coal to buy & \multicolumn{5}{|c|}{0.0} \\
\hline Bond Income & \multicolumn{5}{|c|}{$\$ 6523.53$ USD } \\
\hline Electricity Sold & \multicolumn{5}{|c|}{0.0} \\
\hline Coal Savings & \multicolumn{5}{|c|}{$\$ 7500$ (USD } \\
\hline Fixed Transp. & \multicolumn{5}{|c|}{160.0} \\
\hline Variable Transp. & \multicolumn{5}{|c|}{155.50} \\
\hline Residue Collected & \multicolumn{5}{|c|}{143.823} \\
\hline
\end{tabular}

We have used a hypothetical instance with 20 candidate plots for the collection and transportation of their SCR on a given day. Out of them, only five were attractive enough to be collected. This means that the decision to collect the crop residue is not automatic, it should include the plots that are beneficial to the objective function, and otherwise a model would not be required to collect all plots.

For this instance, the sale of electricity to the grid is not attractive. In an electricity market such as the Colombian, the price of the kwh varies greatly depending on the rains, given that most of the electricity comes from hydropower. This fact makes the use of the model on a daily basis a requirement, since variations on the electricity price might alter the results.

The revenues of the model in this instance come from the green bonds (reductions in pollution levels) and the substitution of coal for crop residue (savings in the purchase of coal). Out of the three possible revenue components of the model (green bonds, coal savings, and sales of electricity), only two are attractive.

In this model, we have been conservative in the estimation of the transportation costs under current forms of operation. In discussions with engineers who work in the harvesting department of sugar cane mills, different forms of operation have been suggested to save on transportation costs, such as hitching additional wagons to sugar cane trains, resulting in smaller marginal transportation costs for the crop residue.

Since the model includes binary variables, it is not possible to use linear programming sensitivity analysis, so building scenarios and observing their results should be the procedure to follow. For this task, a general programming language with an optimization module such as Julia [36] (Appendix A) is a better choice than specialized optimization languages because generating the values of the parameters, running the model multiple times, storing the results, and analyzing the output data are easier in such a language. The instance data is presented in Appendix B.

\section{Discussion}

The authors share the perception that the use of sugarcane crop residue (SCR) has an economic potential that is just beginning to be studied and discovered. The first version of this model is a conservative one, trying not to overestimate the attractiveness of energy cogeneration using the SCR. However, there is a variety of strategies in the preliminary stages of discussion, such as modifying the current harvesting practices to obtain a more compact SCR, in order to transport more weight in less trips. The current practices include manual and mechanized harvesting, so additional treatment of the SCR in the field or the addition of specialized compacting equipment to the harvesters are recommended to reduce the cost of collecting and transporting the SCR. 
Highway infrastructure on the region is in a continuous development process. This fact, added to the previous point, could potentially reduce variable transportation costs in the future and make more plots attractive to harvest their SCR.

The price of electricity that the Colombian grid would pay the sugar mills fluctuates during the day, following the peaks and valleys of electricity consumption in the country. In this sense, the optimal moments to generate electricity and dispatch it to the grid should also be studied to maximize revenues. When sugarcane is harvested, every minute that passes before grinding to extract sugar-bearing juices destroys value, because the usable sugar content decreases over time. This behavior is not the same with SCR, because sugar content is not a variable of interest, and some holding time could be used to let SCR dry and make combustion easier and more productive.

The price of coal is another parameter of interest. For future research, the authors propose to conduct Monte Carlo simulation experiments considering inputs, such as the price of electricity, the price of coal, and the state of the plots (dry or wet if it rains), to design robust decision strategies to maximize the economic and environmental benefit of SCR collection.

Models that can be found in the technical literature sought to maximize profits of the sugarcane mills through the utilization of sugarcane for the production of sugar or ethanol. This model proposes a contribution to the theory of the field by including an alternate use of the sugarcane crop residue, not for the reduction of fertilizers (as it has been studied) but for the substitution of coal to be burned in the boilers and the resulting reduction in pollution and possible revenue through the sale of electricity to the interconnected electricity network of a country.

\section{Conclusions}

For the sugarcane sector, finding alternatives that provide notions of sustainability is fundamental, since its environmental role has always been questioned because of the amount of resources used, from the land itself to the water required for production. The use of their own agricultural residue in the generation of their own energy generates an agribusiness concept based on the conservation of the environment and the efficient use of available resources.

The results obtained look very promising for the sugar industry to the extent that the replacement of fossil fuel (coal) with agricultural crop residues generate a double effect as can be seen. On the one hand, the savings from less coal consumed, taking into account that the mills buy this coal in national and international markets. The price of coal is very volatile and depends on world supply and demand. Savings for substituted coal in this case reach \$7500 USD. Additionally, the replacement of coal generates another very significant effect and is the income obtained from the sale of emission reduction certificates (more than $\$ 6500$ USD).

In Colombia, Law 1715 of 2014 has become a strong incentive for the promotion of projects with non-conventional energy sources. In this context, the sugar sector power cogeneration has become a key element of the national electricity system. Power co-generation plants are backup plants in a predominantly hydropower system. This country has a non-typical behavior, since sugarcane can be sown and harvested all year round, due to the local tropical climate. This characteristic enables the use of SCR as an energy source as a part of day-to-day operations of the sugarcane mills and, thus, as part of the energy generation portfolio for this companies. Sugarcane mills in Colombia are already independent of the energy distributed through the national interconnected network, and the use of SCR would allow them to profit from selling electricity to the public network.

The co-generation of electricity using sugarcane crop residue (SCR) is going to be studied with interest in the near future. This activity shows promise in some specific aspects.

- $\quad \mathrm{SCR}$ releases less equivalent $\mathrm{CO}_{2}$ than coal when burned for electricity generation;

- $\mathrm{SCR}$ is basically free. It is a byproduct of the harvesting of the sugarcane. $\mathrm{CO}_{2}$ is a raw material that has to be acquired through private contracts or the commodities market;

- SCR can be collected using crews, equipment, and vehicles that are similar to those used for the harvesting and transportation of sugarcanes. 
This model is limited by the information it requires to choose a plot over others. Since the Colombian environment allows the harvest of canes throughout the year, there are professionals gathering information and inspecting the growth of the plots to gather the parameters required by the model. This might not be the case in environments with a limited agricultural season.

Also, this model might require adaptations for use in areas with seasonal weather. The crop residue would be collected in a shorter time frame and some storage costs would be accrued to use the residue for electricity generation spread throughout more months of the year.

It would also be interesting to use this model to study the impact of the price of coal, electricity, and green bonds on the decision to collect and transport residue. A time-series analysis or econometric study of the data of these prices would be required as part of the analysis.

Author Contributions: All authors contributed in this paper. P.C.M.-V. collected the data and developed the conceptual model. D.F.M.-D. developed the economic model. L.R.-C. developed the methodology and mathematical model. All authors contributed in the results analysis and writing.

Funding: This research received no external funding

Acknowledgments: All authors acknowledge the School of Industrial Engineering at the Universidad del Valle for the support to develop this paper.

Conflicts of Interest: All authors declare no conflict of interest.

\section{Appendix A}

Julia Code

using JuMP

using GLPK

using MathoptInterface

using CSV

\# Read data from file

data $=$ CSV.read("Model-Data.csv")

\# Create indexed parameters

$\mathrm{TCR}=$ data. $\mathrm{TCR}$

$\mathrm{CP}=\operatorname{data} \cdot \mathrm{CP}$

$P=\operatorname{data} . P$

$\mathrm{D}=\operatorname{data} \cdot \mathrm{D}$

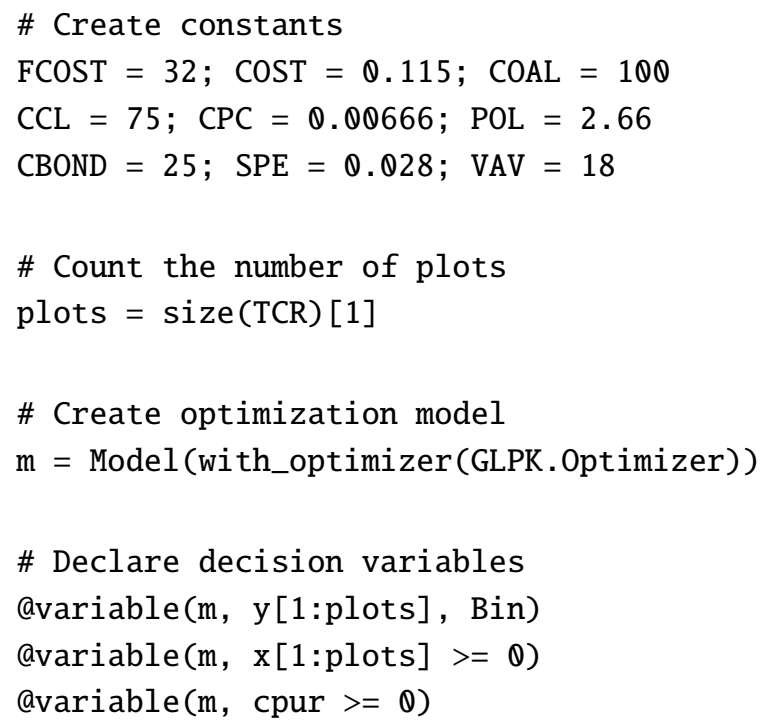


\# Declare cost variables for the objective function

Qvariable (m, bond_income $>=0)$

Qvariable(m, elec_sold $>=0)$

Qvariable(m, coal_savings $>=0$ )

Qvariable(m, fixed_transp $>=0$ )

Qvariable(m, var_transp >= 0$)$

\# Declare the objective function

Qobjective(m, Max, bond_income + elec_sold + coal_savings - fixed_transp -

var_transp)

\# The new level of pollution must not exceed the baseline

@constraint (m, pol_base, cpur*POL $+\operatorname{sum}(x[i] * P[i]$ for $i$ in $1: p l o t s)<=$ COAL*POL)

\# The electricity generated must not be less than the baseline

aconstraint $(m$, elec_gen, $\operatorname{sum}(x[i] * C P[i]$ for $i$ in $1:$ plots $)+($ cpur*CPC) $>=C O A L * C P C)$

\# The number of plots to collect crop residue is limited by

\# the number of trips available per day

aconstraint (m, collect_plots, sum(y[i] for $i$ in $1: p l o t s)<=V A V)$

\# If a plot is not selected, no crop residue can be collected from it

aconstraint (m, residue $[i=1:$ plots $], x[i]<=\mathrm{TCR}[i] * y[i])$

\# Assign value to the cost variables of the objective function

aconstraint $(m$, bondincome, bond_income $==(C O A L * P O L-\operatorname{sum}(x[i] * P[i]$ for $i$ in

$1:$ plots) - cpur*POL) * (BOND)

(constraint $(m$, elecsold, elec_sold $==(\operatorname{sum}(x[i] * \mathrm{CP}[i]$ for $i$ in $1: p l o t s)+$

$(($ cpur-COAL $) * \mathrm{CPC})) * \mathrm{SPE})$

Qconstraint $(m$, coalsavings, coal_savings $==($ COAL - cpur $) * C C L)$

@constraint (m, fixedtransp, fixed_transp $==\operatorname{sum}(y[i] * F C O S T$ for $i$ in 1:plots))

Qconstraint (m, vartransp, var_transp $==\operatorname{sum}(x[i] * D[i] * \operatorname{CosT}$ for $i$ in $1: p l o t s)$ )

$\operatorname{print}(\mathrm{m})$

status $=$ optimize $!(\mathrm{m})$

println("Profit: ", JuMP.objective_value(m))

println("Plots to collect: ", JuMP.value.(y))

println("Crop residue: ", JuMP.value.(x))

println("Coal to buy: ", JuMP.value(cpur))

println("Bond Income: ", JuMP.value(bond_income))

println("Electricity Sold: ", JuMP.value(elec_sold))

println("Coal Savings: ", JuMP.value(coal_savings))

println("Fixed Transp: ", JuMP.value(fixed_transp))

println("Variable Transp: ", JuMP.value(var_transp))

println("Residue Collected: ", sum(JuMP.value.(x))) 


\section{Appendix B}

Instance Data

Table A1. Instance data.

\begin{tabular}{ccccc}
\hline Plot. & TCR & CP & P & D \\
\hline P1 & 37 & 0.0030336 & 0.0352 & 17.14 \\
P2 & 30 & 0.0032734 & 0.0334 & 3.42 \\
P3 & 26 & 0.0058655 & 0.0363 & 21.16 \\
P4 & 39 & 0.0041573 & 0.0331 & 15.65 \\
P5 & 26 & 0.0032552 & 0.0361 & 3.24 \\
P6 & 35 & 0.0032061 & 0.0338 & 15.31 \\
P7 & 37 & 0.0057260 & 0.0347 & 22.56 \\
P8 & 33 & 0.0040761 & 0.0345 & 21.03 \\
P9 & 21 & 0.0059792 & 0.0336 & 5.55 \\
P10 & 33 & 0.0037543 & 0.036 & 24.73 \\
P11 & 33 & 0.0052091 & 0.0354 & 17.78 \\
P12 & 32 & 0.0044785 & 0.0333 & 22.54 \\
P13 & 27 & 0.0030945 & 0.0343 & 11.12 \\
P14 & 27 & 0.0044857 & 0.0363 & 16.47 \\
P15 & 30 & 0.0046803 & 0.0353 & 22.67 \\
P16 & 36 & 0.0054730 & 0.0367 & 13.91 \\
P17 & 24 & 0.0042343 & 0.034 & 22.60 \\
P18 & 23 & 0.0039274 & 0.0349 & 14.76 \\
P19 & 30 & 0.0044093 & 0.0341 & 22.49 \\
P20 & 26 & 0.0055547 & 0.0353 & 16.93 \\
\hline
\end{tabular}

\section{References}

1. Biomass Energy Resource Center Home Page. Available online: https://www.biomasscenter.org/ (accessed on 12 November 2019).

2. Perea-Moreno, M.-A.; Samerón-Manzano, E.; Perea-Moreno, A.-J. Biomass as renewable energy: Worldwide research trends. Sustainability 2019, 11, 863. [CrossRef]

3. Sharma, B.; Ingalls, R.G.; Jones, C.L.; Khanchi, A. Biomass supply chain design and analysis: Basis, overview, modeling, challenges, and future. Renew. Sustain. Energy Rev. 2013, 24, 608-627. [CrossRef]

4. Yue, D.; You, F.; Snyder, S.W. Biomass-to-bioenergy and biofuel supply chain optimization: Overview, key issues and challenges. Comput. Chem. Eng. 2014, 66, 36-56. [CrossRef]

5. De Meyer, A.; Cattrysse, D.; Rasinmäki, J.; Van Orshoven, J. Methods to optimise the design and management of biomass-for-bioenergy supply chains: A review. Renew. Sustain. Energy Rev. 2014, 31, 657-670. [CrossRef]

6. Cambero, C.; Sowlati, T. Assessment and optimization of forest biomass supply chains from economic, social and environmental perspectives-A review of literature. Renew. Sustain. Energy Rev. 2014, 36, 62-73. [CrossRef]

7. Sindhu, R.; Gnansounou, E.; Binod, P.; Pandey, A. Bioconversion of sugarcane crop residue for value added products-An overview. Renew. Energy 2016, 98, 203-215. [CrossRef]

8. Sector Agroindustrial de la Caña. Informe Anual 2018-2019. Available online: https://www.asocana.org/ modules/documentos/3/362.aspx (accessed on 29 October 2019).

9. Go, A.W.; Conag, A.T.; Igdon, R.M.B.; Toledo, A.S.; Malila, J.S. Potentials of agricultural and agro-industrial crop residues for the displacement of fossil fuels: A Philippine context. Energy Strategy Rev. 2019, 23, 100-113. [CrossRef]

10. Cervi, W.R.; Lamparelli, R.A.C.; Seabra, J.E.A.; Junginger, M.; van der Hilst, F. Bioelectricity potential from ecologically available sugarcane straw in Brazil: A spatially explicit assessment. Biomass Bioenergy 2019, 122, 391-399. [CrossRef]

11. Khatiwada, D.; Leduc, S.; Silveira, S.; McCallum, I. Optimizing ethanol and bioelectricity production in sugarcane biorefineries in Brazil. Renew. Energy 2016, 85, 371-386. [CrossRef] 
12. Olivério, J.L.; Ferreira, F.M. Cogeneration-A new source of income for sugar and ethanol mills or bioelectricity-A new business. Proc. Int. Soc. Sugar Cane Technol. 2010, 27.

13. Bocci, E.; Di Carlo, A.; Marcelo, D. Power plant perspectives for sugarcane mills. Energy 2009, 34, 689-698. [CrossRef]

14. Hiloidhari, M.; Araújo, K.; Kumari, S.; Baruah, D.C.; Ramachandra, T.V.; Kataki, R.; Thakur, I.S. Bioelectricity from sugarcane bagasse co-generation in India-An assessment of resource potential, policies and market mobilization opportunities for the case of Uttar Pradesh. J. Clean. Prod. 2018, 182, 1012-1023. [CrossRef]

15. Pierossi, M.A.; Bertolani, F.C. Sugarcane trash as feedstock for biorefineries: Agricultural and logistics issues. In Advances in Sugarcane Biorefinery: Technologies, Commercialization, Policy Issues and Paradigm Shift for Bioethanol and By-Products; Chandel, A.K., Silveira, M.H.L., Eds.; Elsevier: Amsterdam, The Netherlands, 2017; pp. 17-39.

16. León-Martinez, T.; Dopíco-Ramírez, D.; Triana-Hernández, O.; Medina-Estevez, M. Sobre los Derivados de la Caña de Azúcar; ICIDCA: Habana, Cuba, 2013; Volume 47, pp. 13-22.

17. Cobo-Barrera, D.F. Pirólisis de Residuos de Cosecha de Caña de Azúcar (RAC) como Alternativa de Aprovechamiento en Procesos de Cogeneración. Master's Thesis, Universidad del Valle, Cali, Colombia, May 2012.

18. Ojeda, W.; Saltaren, J.; Lucuara, J.; Gómez, A.; Gil, N. Valorización de residuos agrícolas de cosecha (RAC) de caña de azúcar mediante densificación mecánica. In Proceedings of the XI Congreso Atalac-Tecnicaña, Cali, Colombia, 24-28 September 2018; pp. 488-496.

19. Zandi Atashbar, N.; Labadie, N.; Prins, C. Modelling and optimisation of biomass supply chains: A review. Int. J. Prod. Res. 2018, 56, 3482-3506. [CrossRef]

20. Flores Hernández, U.; Jaeger, D.; Islas Samperio, J. Bioenergy potential and utilization costs for the supply of forest woody biomass for energetic use at a regional scale in Mexico. Energies 2017, 10, 1192. [CrossRef]

21. Hofsetz, K.; Silva, M.A. Brazilian sugarcane bagasse: Energy and non-energy consumption. Biomass Bioenergy 2012, 46, 564-573. [CrossRef]

22. Rentizelas, A.A.; Tolis, A.J.; Tatsiopoulos, I.P. Logistics issues of biomass: The storage problem and the multi-biomass supply chain. Renew. Sustain. Energy Rev. 2009, 13, 887-894. [CrossRef]

23. Agustina, F.; Vanany, I.; Siswanto, N. Biomass Supply Chain Design, Planning and Management: A Review of Literature. In Proceedings of the 2018 IEEE International Conference on Industrial Engineering and Engineering Management, Bangkok, Thailand, 16-19 December 2018; pp. 884-888.

24. Smithers, J. Review of sugarcane trash recovery systems for energy cogeneration in South Africa. Renew. Sustain. Energy Rev. 2014, 32, 915-925. [CrossRef]

25. Florentino, H.D.O.; De Lima, A.D.; De Carvalho, L.R.; Balbo, A.R.; Homem, T.P.D. Multiobjective 0-1 integer programming for the use of sugarcane residual biomass in energy cogeneration. Int. Trans. Oper. Res. 2011, 18, 605-615. [CrossRef]

26. Carvajal, J.; Sarache, W.; Costa, Y. Addressing a robust decision in the sugarcane supply chain: Introduction of a new agricultural investment project in Colombia. Comput. Electron. Agric. 2019, 157, 77-89. [CrossRef]

27. Higgins A., J.; Laredo, L.A. Improving harvesting and transport planning within a sugar value chain. J. Oper. Res. Soc. 2006, 57, 367-376. [CrossRef]

28. López-Milán, E.; Plà-Aragonés, L.M. A decision support system to manage the supply chain of sugar cane. Ann. Oper. Res. 2014, 219, 285-297. [CrossRef]

29. López-Milán, E.; Plà-Aragonés, L.M. Optimization of the supply chain management of sugarcane in Cuba. Int. Ser. Oper. Res. Manag. Sci. 2015, 224, 107-127.

30. Go, A.W.; Conag, A.T. Utilizing sugarcane leaves/straws as source of bioenergy in the Philippines: A case in the Visayas Region. Renew. Energy 2019, 132, 1230-1237. [CrossRef]

31. Alonso-Pippo, W.; Luengo, C.A.; Felfli, F.F.; Garzone, P.; Cornacchia, G. Energy recovery from sugarcane biomass residues: Challenges and opportunities of bio-oil production in the light of second generation biofuels. J. Renew. Sustain. Energy 2009, 1, 063102. [CrossRef]

32. Portugal-Pereira, J.; Soria, R.; Rathmann, R.; Schaeffer, R.; Szklo, A. Agricultural and agro-industrial residues-to-energy: Techno-economic and environmental assessment in Brazil. Biomass Bioenergy 2015, 81, 521-533. [CrossRef] 
33. Roca, R. El precio del $\mathrm{CO}_{2}$, imparable: Marca un nuevo récord por encima de €27 por tonelada, el doble que hace un año. El Periodico de la Energía. 12 April 2019. Available online: https://elperiodicodelaenergia.com/el-precio-del-co2-imparable-marca-un-nuevo-record-porencima-de-27-e-por-tonelada-el-doble-que-hace-un-ano/ (accessed on 30 October 2019).

34. Castillo, J.L.; Lucuara, J.E. Uso de residuos agrícolas de cosecha (RAC) como combustible no convencional para generar energía eléctrica en calderas de potencia. In Proceedings of the 3er. Encuentro de Usuarios de Calderas Colombia, Bogota, Colombia, 12-13 May 2016. Available online: https://www.ceaca.com/wp-content/uploads/ 2016/06/7-USO-DE-RESIDUOS-AGRICOLAS-DE-COSECHA-COMO-COMBUSTIBLE.pdf (accessed on 17 November 2019).

35. Fuentes renovables tendrían participación del 8\% en la torta energética nacional. La República. 23 October 2019. Available online: https://www.larepublica.co/economia/fuentes-renovables-tendran-participacion-del8-en-la-torta-energetica-nacional-2923630 (accessed on 29 October 2019).

36. Bezanson, J.; Edelman, A.; Karpinski, S.; Shah, V.B. Julia: A fresh approach to numerical computing. Siam Rev. 2017, 59, 65-98. [CrossRef]

(C) 2019 by the authors. Licensee MDPI, Basel, Switzerland. This article is an open access article distributed under the terms and conditions of the Creative Commons Attribution (CC BY) license (http://creativecommons.org/licenses/by/4.0/). 